Blockchains and Cryptocurrencies

Network hype and asset pricing of cryptocurrencies: evidence based on a Google-attention approach

Aifan Ling and Zhikai Zhu

DOI: $\underline{10.1504 / / J B C .2021 .117812}$

\section{Article History:}

Received:

Last revised:

Accepted:

Published online:
International Journal of Blockchains and Cryptocurrencies

ISSN online: 2516-6433 - ISSN print: 2516-6425

https://www.inderscience.com/ijbc 


\title{
Network hype and asset pricing of cryptocurrencies: evidence based on a Google-attention approach
}

Aifan Ling* and Zhikai Zhu

School of Finance, Jiangxi University of Finance and Economics, Nanchang 330013, China

Email: aifanling@jxufe.edu.cn

Email: zzk199487@qq.com

*Corresponding author

\begin{abstract}
The rapid development of cryptocurrencies motivates us to examine the factors that drive cryptocurrency prices. Using Google attention innovation to measure network hype or investor speculation, this paper investigates the effect of network hype in the cryptocurrency market and proposes a three-factor asset pricing model composed of the market, size, and network hype factors. This paper is the first empirical study on asset pricing in cryptocurrency markets and is a unique attempt to value the cryptocurrencies prices using a factor model. The empirical results show: 1) there is a positive and significant effect of network hype in the cryptocurrency market, and network hype plays a significant role in increasing cryptocurrency prices; 2) average excess returns of cryptocurrencies are negatively correlated with their size and have a significant positive correlation with Google attention innovation; 3) our three-factor model has strong explanatory power for excess cryptocurrency returns and can explain the momentum, reversal, and liquidity factors in the cryptocurrency market.
\end{abstract}

Keywords: cryptocurrency; asset pricing; network hype; three-factor model; Google attention.

Reference to this paper should be made as follows: Ling, A. and Zhu, Z. (2021) 'Network hype and asset pricing of cryptocurrencies: evidence based on a Google-attention approach', Int. J. Blockchains and Cryptocurrencies, Vol. 2, No. 1, pp.19-43.

Biographical notes: Aifan Ling's research interests include asset pricing, risk management, blockchain and cryptocurrency.

Zhikai Zhu's research interests include asset pricing and cryptocurrency.

This paper is a revised and expanded version of a paper entitled 'Network hype and asset pricing of cryptocurrencies' presented at the 2nd FinTech Conference, JUFE, 27 April 2019. 


\section{Introduction}

\subsection{Background and motivation}

Since Nakamoto (2008) designed the first form of peer-to-peer digital cash, Bitcoin. New cryptocurrencies have been issued and globally traded as a special class of risky assets (see Corbet et al., 2019). These cryptocurrencies have increased in popularity among international investors. A total of 1,881 cryptocurrencies had been traded as of 31 July 2018, in CoinMarketCap, an influential provider of cryptocurrency data, and the number of cryptocurrencies continues to increase rapidly. Cryptocurrencies are traded on the cryptocurrency market. In contrast to traditional stock markets, the cryptocurrency market is a 24/7-hour trading mechanism. Some investors purchase cryptocurrencies directly using legal tender, and some investors obtain cryptocurrencies by 'mining' as 'miners'. Issuing a new cryptocurrency is easier than issuing a stock because issuing a new cryptocurrency seldom requires regulatory approval.

Another important difference between the cryptocurrency and stock markets is that the issuers of cryptocurrencies are not required to provide corporate financial data. Typically, trading cryptocurrencies is riskier than trading stocks. For example, the price of Bitcoin reached $\$ 20,000$ at the end of 2017 and rapidly dropped to $\$ 10,775.92$ within a quarter. Bitcoin lost almost half its market value with a decline of close to 1,700 points per day. In 2018, the price of Bitcoin experienced three consecutive drops and finally fell below $\$ 4,000$. The fluctuations in Bitcoin reflect that the risk in the cryptocurrency market is greater than the risk in the stock market.

The surprising expansion of the cryptocurrency market motivates us to ask what factors determine the prices of cryptocurrencies. In other words, is there an asset pricing model, as there is for the stock market, to value cryptocurrency prices? This line of investigation could help to determine the risk factors in the cryptocurrency market and explain its operating mechanism. A natural problem is whether all pricing factors in the stock market can be applied to the cryptocurrency market. Lack of financial and accounting data for cryptocurrencies means that some pricing factors in the equity market are not suitable for the cryptocurrency market. For instance, the book-to-market (B/M) (Fama and French, 1992), profit, and investment factors (Fama and French, 2015) for the stock market are calculated using financial and accounting data. This problem motivates us to find more suitable factors to construct an asset pricing model for the cryptocurrency market.

\subsection{Contribution}

Based on the daily prices of cryptocurrencies from 1 July 2016 to 31 July 2018 and the cross-sectional returns for 1,314 cryptocurrencies, we consider the impacts of size, reversal, momentum, and the weekly maximum daily return rate on the expected cryptocurrency returns in this paper. Particularly, we check the existence of the 'network hype effect' measured by Google attention to cryptocurrencies. Following the approach of the Fama-French three-factor model, we construct a new three-factor model for the cryptocurrency market: the cryptocurrency market index factor, size factor, and 'network hype' factor. The main empirical results and contributions of this paper include: 
1 We use Google attention innovation, $G A I$, to measure the degree of network hype. We find that $G A I$ at week $t$ has a significantly positive relation with the expected cryptocurrency returns at week $t+k(1 \leq k \leq 3)$. We call this the network hype effect (or network attention effect). Network hype plays a key role in increasing the value of cryptocurrency. This motivates us to use $G A I$ to construct a network hype factor for the cryptocurrency market, which is a key factor in our model.

2 The expected excess cryptocurrency returns are negatively related to the size of the cryptocurrency. This is similar to the findings of the Fama-French three-factor model for the stock market. We study the momentum of cryptocurrency returns by sorting all cryptocurrencies based on their returns during the past three weeks and find that there is no significant momentum effect in the cross-sectional expected cryptocurrency returns. This differs from the stock market (Carhart, 1997; Jegadeesh and Titman, 1993) and is also different from the time-series momentum effect of cryptocurrencies (Liu and Tsyvinski, 2018). We also consider cryptocurrency liquidity. Unlike the equity markets (O'Hara, 2003), the empirical results show that the liquidity factor has little impact on cryptocurrency returns.

3 We also consider reversal returns and weekly maximum daily returns. We find common results for the reversal and maximum daily return effects: both effects are not significant in the full samples but are significant in the small-size group. Cryptocurrencies with high reversal returns have significantly high expected returns, and cryptocurrencies with high weekly maximum daily returns have significantly high expected return in the following week.

4 We propose a new three-factor pricing model composed of the market, size, and network hype factor based on cryptocurrency market data. The empirical results show that the proposed three-factor pricing model explains the expected cryptocurrency excess returns. For example, in the 25 portfolios based on the $5 * 5$ cross groups of size and Google attention innovation, the number of significant alphas is only two out of 25 at the $1 \%$ level, but the number of the significant alphas is 17 out of 25 for CAPM at the same confidence level.

5 We also construct the momentum factor, the liquidity factor, and the reversal factor using the cryptocurrency data, and we find several interesting empirical results. First, the performance of the proposed three-factor model is improved only weakly when both momentum and liquidity factors are added to the pricing model. Second, the proposed three-factor model can explain both momentum and liquidity factors. Third, and most importantly, the proposed three-factor model can also explain the return anomalies caused by both momentum and liquidity factors in the small-size samples.

\subsection{Related research literature}

As an emerging capital market, the cryptocurrency market has attracted many scholars who are monitoring its risks, investment opportunities, and ICO mechanism. Among theoretical studies, Malinova and Park (2017) study the cryptocurrency market mechanism design problem. Li and Mann (2018) propose a theoretical model of the impact of network platforms on ICO. Sockin and Xiong (2018) theoretically analyse the factors that determine cryptocurrency prices. Tinn (2018) studies blockchain and 
optimal contract theory. Iyidogan (2018) investigates the blockchain problem from the perspective of economic theory. More theoretical research on cryptocurrencies and blockchain can be found in Athey et al. (2016), Biais et al. (2019) and Cong et al. (2018).

In the empirical research, on the one hand, the studies on risk, investment, and arbitrage in the cryptocurrency market have attracted substantial attention. For example, Saleh (2018) studies the welfare and risks of cryptocurrencies. Stavroyiannis (2018) uses the traditional value at risk (VaR) method to measure the risks of Bitcoin. Borri (2019) explores the tail risks of cryptocurrencies. From the perspective of investors, Borri and Shakhnov (2018) study the relationship between legal tender and cryptocurrency as well as the construction of investment strategy. Hu et al. (2018) and Antonakakis et al. (2019) explore the relationship between cryptocurrency prices and the arbitrage opportunities in the market. Using daily data, Urquhart and Zhang (2018) design risk-hedging strategies for cryptocurrencies. Makarov and Schoar (2018) study the market effectiveness and price formations of cryptocurrencies and further discuss the price determination and arbitrage problems of cryptocurrencies when traded on different exchanges. On the other hand, the return anomalies and asset allocations of cryptocurrencies have also attracted substantial attention from researchers (e.g., Aloosh and Ouzan, 2019; Caporale and Plastun, 2019; Elendner et al., 2018; Klein et al., 2018; Yang, 2019). As an emerging market, cryptocurrency's efficiency is clearly a valuable and interesting field and a focus of many studies (e.g., Bariviera, 2017; Borri and Shakhnov, 2019; Köchling et al., 2019; Kristoufek, 2018; Liu et al., 2019; Nadarajah and Chu, 2017; Urquhart, 2016; Yong et al., 2018; Cheng and Dai, 2020).

Our work can be classified as part of the empirical research on empirical asset pricing and its contributions are twofold. On the one hand, we find two new anomalies. On the other hand, we provide an asset pricing model for the cryptocurrency market. This differentiates our study from the current empirical asset pricing literature that focuses on the stock, bond, and derivatives markets such as Fama and French (2015), Hou et al. (2015) and Barillas and Sheanken (2018). Few studies focus on asset pricing in the cryptocurrency market. Our work is a new attempt to value cryptocurrency prices using the factor model.

Our work is related to the recent paper of Liu and Tsyvinski (2018). In their paper, Liu and Tsyvinski (2018) explore the explanatory power of stock market factors concerning cryptocurrency returns. The pricing factors that the authors consider are calculated using stock market data. Stock market pricing factors have weak explanatory power for the expected excess cryptocurrency returns. Thus, there are many differences between our paper and Liu and Tsyvinski's (2018) work. Using cryptocurrency market data instead of equity market data, we first study the effects of size, network hype (or network attention), momentum, reversal, and liquidity risk in the cross-section expected returns with a large sample of the cryptocurrency market while Liu and Tsyvinski (2018) consider only the effects of three cryptocurrencies at the time series level. Second, we find that the momentum effect does not exist in the cross-section of expected returns, but the momentum effect exists for the time series data. Third, we propose a three-factor pricing model for the cryptocurrency market that has a strong ability to explain excess cryptocurrency returns. Liu and Tsyvinski's (2018) study values the prices of cryptocurrencies directly using stock market pricing factors. Fourth, we discuss the performance of the proposed pricing model, which is not considered by Liu and Tsyvinski (2018). 
Our work also differs from Kristoufek's (2013) paper, in which the author uses the results of a Google Trends search and Wikipedia as investor sentiment. The author finds a relationship between Bitcoin prices and related searched terms on Google Trends and Wikipedia and a striking positive correlation between the Bitcoin price level and the searched terms as well as a bidirectional dynamic relationship. The positive relationship between Bitcoin prices and Google Trends is consistent with our findings. However, our paper does not shop this result. We further find relationships between other cryptocurrency prices and Google Trends and provide a three-factor pricing model with Google Trends as the sentiment factor of investors.

The remainder of the paper is arranged as follows. We first introduce some variables and explain how we selected the pricing factors including network search attention as a proxy of the degree of network hype in Sections 2 and 3. We then combine size and Google attention to construct the pricing model in Section 4 . We verify the performance of the three-factor model in Section 5.

\section{Data and variables}

\subsection{Data}

In the cryptocurrency market, cryptocurrency prices differ depending on the trading exchange or platform. In other words, there is no unified price for cryptocurrency traded on different platforms. This complicates the calculations for cryptocurrency returns. We unify the prices on the different platforms using a volume-weights approach. We assume that there are $J$ platforms trading cryptocurrency $i$. The price of cryptocurrency $i$ traded on the $j^{\text {th }}$ platform at time $t$ is denoted by $P_{j, i, t}$. We denote the volume of cryptocurrency $i$ traded on the $j^{\text {th }}$ platform in the last 24 hours as $V O L_{j, i, t-24}$ hour. We calculate the price of cryptocurrency $i$ at time $t$ as follows.

$$
P_{i, t}=\sum_{j=1}^{J} \frac{V_{j=1} L_{j, i, t-24 \text { hour }}}{\sum_{j=1}^{j=J} V_{j, i, t-24 \text { hour }}} \times P_{j, i, t} .
$$

Price $P_{i, t}$ of cryptocurrency $i$ at time $t$ is determined by the weight, which is the ratio of the volume of platform $j$ relative to the total volume for this asset on all $J$ platforms multiplied by its price on platform $j$ over the last 24 hours. The return on cryptocurrency $i$ at time $t$ is calculated by its price $P_{i, t}$ :

$$
R_{i, t}=\frac{P_{i, t-1}}{P_{i, t}}-1
$$

Our data cover the time horizon from 1 July 2016 to 31 July 2018, with a total of 109 weeks of daily returns. After excluding the samples whose market value is less than $\$ 10,000$ to consider the stability of the return, we obtain a total of 1,314 cryptocurrencies. All of the data above are from CoinMarketCap: https://coinmarketcap.com/.

\subsection{Variables selection}

As mentioned in the introduction, Liu and Tsyvinski (2018) find that stock market pricing factors cannot explain cryptocurrency excess returns. This inspires us to 
study the pricing factors based on the cryptocurrency market itself. Note that all cryptocurrencies have no financial data. Thus, some factors that require financial and accounting data, as in the stock market, cannot be used to construct cryptocurrency pricing factors due to the lack of financial data. For example, the $\mathrm{B} / \mathrm{M}$ ratio factor in Fama and French's (1992) three-factor model cannot be constructed for the cryptocurrency market because doing so requires the book value of the asset. The investment and profit factors in Fama and French's (2015) five-factor model cannot be directly constructed for the cryptocurrency market because these factors require firms' financial data (returns on equity and total assets). It is possible to base cryptocurrency pricing factors on returns or trading volumes. Thus, we attempt to consider the following cryptocurrency market variables.

\subsubsection{The cryptocurrency market return}

Inspired by the traditional CAPM model, the first variable we consider is the cryptocurrency market return. We set the market return as the weighted average returns for all cryptocurrencies. The weight of cryptocurrency $i$ at time $t$ is labeled $w_{i, t}$, which is proportional to the market capitalisation of cryptocurrency $i$. Thus, the market index return is calculated as follows:

$$
R_{m, t}=\sum w_{i, t} R_{i, t}
$$

\subsubsection{The size factor}

Company size is one of the important variables of the Fama-French factor models. This leads us to consider whether there is a similar size effect in the cryptocurrency market. Similar to the definition of the equity market, the size of cryptocurrency $i$ is its price multiplied by the total amount of the cryptocurrency in the market, but the amount of each cryptocurrency is increasing because there are many miners mining cryptocurrency at any time. The increasing amount of cryptocurrency will affect the size even though the price remains unchanged. To control the impact of the changing amount of cryptocurrency on size, we smooth the amount of the cryptocurrency in the sample horizon. Note that the sample horizon is from 1 July 2016 to 31 July 2018. The number of any cryptocurrency on 31 July 2018 is the largest in the sample horizon. We divide the amount of cryptocurrency on 31 July 2018 by the number of trading dates in the sample horizon. The quotient is set as the amount of cryptocurrency on each trading date in the sample horizon. For instance, we assume that the amount of cryptocurrency $i$ is $N_{i}$, and there are $T_{i}$ trading dates in the sample horizon from 1 July 2016 to 31 July 2018. Then, at each trading date, we set the amount of cryptocurrency $i$ as approximately

$$
\bar{N}_{i}=\frac{N_{i}}{T_{i}}
$$

Then, the size of cryptocurrency $i$ at time $t$ is calculated by its price $P_{i, t}$ times $\bar{N}_{i}$, namely,

$$
M E_{i, t}=P_{i, t} \times \bar{N}_{i}
$$




\subsubsection{Network attention}

In the stock market, the rich empirical research shows that investors' attention to risky assets can significantly affect the returns for risky assets. Cryptocurrencies have recently received widespread attention and many have paid close attention to the developments in this new field since Bitcoin's emergence. The impact of network attention on the price of stocks inspires us to test whether network attention on cryptocurrencies can also affect the prices of cryptocurrencies. We use Google attention (Google Trends) to measure investor network attention on cryptocurrencies because Google attention is a widely accepted index for the measurement of attention in many studies, for example, Da et al. (2011) and Takeda and Wakao (2014).

For a Google Trends search, if we input a keyword, for example, Bitcoin, Google Trends returns the changes in attention for the keyword. Generally, the Google Trend Index represents the degree of network attention relative to the specified area in the chart and the highest point in the specified time. A trending word can receive 100 points, the highest degree of network attention. Fifty points mean half of the highest amount of attention. A word with zero points means that there is insufficient data or no network attention on Google Trends. We denote Google attention denoted by $G A_{i, t}$ at time $t$ for cryptocurrency $i$, and Google attention innovation between time $t-1$ and $t, G A I$, is denoted by

$$
G A I=G A_{i, t}-G A_{i, t-1}
$$

\subsubsection{Liquidity}

Liquidity is an important variable for risky asset prices in equity and other capital markets (Amihud, 2002; O'Hara, 2003). We consider the liquidity variable of the cryptocurrency market. We define the liquidity of cryptocurrency $i$ at time $t$ as the ratio of the market capitalisation at time $t$ to the total transaction volume at the same time and denote it by $L i q_{i, t}$.

\subsubsection{Reversal and momentum}

The weekly reversal return of cryptocurrency $i$ is marked as $r_{S T R, i, t}$ and is defined as the return of cryptocurrency $i$ in week $t-1$. Similarly, we define the weekly momentum return $r_{M O M, i, t}$ as the sum of the returns for cryptocurrency $i$ from weeks $t-4$ to $t-2$. We do not add the returns for week $t-1$ into the momentum variable for the sake of eliminating the reversal effect.

\subsubsection{Maximum daily return per week}

Bali et al. (2011) find that the maximum daily return on the stock market in the previous month has a significant impact on the cross-sections of the expected asset returns in the next month. Inspired by their work, we introduce the maximum daily return cryptocurrency variable in week $t$ and denote it by $R_{M A X, i, t}$. We check the impact of the maximum daily cryptocurrency returns in the previous week $t$ on the cross-sections of the expected returns in the following week. ${ }^{1}$ 
We calculate the value-weighted average weekly returns for decile portfolios that are formed by sorting the cryptocurrencies based on the foregoing six variables and the Google attention innovation $G A I$ at each week. Table 1 reports the average weekly returns for the decile portfolios. Table 1 shows that, first, the market capitalisation of the cryptocurrency is negatively related to the portfolio returns. The average return is $25.29 \%$ per week at the low ME portfolio, and reduces to $3.51 \%$ per week at the high ME portfolio. The long-short portfolio ( $L-H$ portfolio) can obtain a weekly return of $21.75 \%$ with a $t$-statistic of 4.8266 , which is significant at the $1 \%$ level. See the last row of Table 1 . Hence, there is a significant size effect in the cryptocurrency market.

Table 1 Portfolio returns based on the sorted factors

\begin{tabular}{lccccccc}
\hline Rank & $r_{M E}$ & $r_{G A}$ & $r_{G A I}$ & $r_{L i q}$ & ${ }^{*} r_{M A X}$ & $r_{S T R}$ & $r_{M O M}$ \\
\hline Low & 0.2529 & 0.0347 & -0.0349 & 0.0479 & 0.0341 & 0.0827 & 0.0637 \\
& $(5.3278)$ & $(2.0441)$ & $(-1.4408)$ & $(2.1327)$ & $(2.3925)$ & $(3.1605)$ & $(1.7874)$ \\
2 & 0.1270 & 0.0544 & -0.0290 & 0.0511 & 0.0377 & 0.0298 & 0.0473 \\
& $(4.7895)$ & $(2.9788)$ & $(-1.6323)$ & $(2.8942)$ & $(2.2299)$ & $(1.4626)$ & $(2.2324)$ \\
3 & 0.21113 & 0.0299 & -0.0042 & 0.0515 & 0.0588 & 0.0302 & 0.0494 \\
& $(2.3537)$ & $(1.5889)$ & $(-0.2417)$ & $(2.6438)$ & $(2.8257)$ & $(1.5475)$ & $(2.8620)$ \\
4 & 0.1276 & 0.0438 & -0.0265 & 0.0441 & 0.0692 & 0.0597 & 0.0391 \\
& $(4.3548)$ & $(1.8371)$ & $(-1.8109)$ & $(1.9312)$ & $(2.9081)$ & $(1.5856)$ & $(1.7423)$ \\
5 & 0.1177 & 0.0789 & 0.0213 & 0.0965 & 0.0425 & 0.0245 & 0.0412 \\
& $(4.6068)$ & $(1.8087)$ & $(1.3557)$ & $(2.5687)$ & $(2.1115)$ & $(1.5371)$ & $(2.5142)$ \\
6 & 0.0828 & 0.0389 & 0.0908 & 0.0393 & 0.0493 & 0.0473 & 0.0657 \\
& $(3.9697)$ & $(1.8470)$ & $(3.4478)$ & $(1.9334)$ & $(2.2286)$ & $(2.6743)$ & $(3.0498)$ \\
7 & 0.0842 & 0.0526 & 0.0983 & 0.0428 & 0.0452 & 0.0626 & 0.0711 \\
& $(3.8667)$ & $(2.1676)$ & $(3.8419)$ & $(1.8113)$ & $(1.7585)$ & $(3.1241)$ & $(1.6446)$ \\
8 & 0.0633 & 0.0550 & 0.1975 & 0.1462 & 0.1807 & 0.0923 & 0.0502 \\
& $(3.3153)$ & $(2.7335)$ & $(2.5665)$ & $(1.6473)$ & $(2.0994)$ & $(2.3679)$ & $(2.6766)$ \\
9 & 0.0456 & 0.0747 & 0.2204 & 0.0748 & 0.0689 & 0.0605 & 0.0356 \\
& $(2.4847)$ & $(2.5174)$ & $(4.7455)$ & $(3.5291)$ & $(1.7972)$ & $(2.4846)$ & $(1.7235)$ \\
High & 0.0351 & 0.0606 & 0.4204 & 0.1145 & 0.0864 & 0.0702 & 0.0438 \\
& $(2.6918)$ & $(2.5977)$ & $(5.5178)$ & $(2.2939)$ & $(1.5972)$ & $(1.4294)$ & $(1.5376)$ \\
\hline Diff & $0.2175 * * *$ & 0.0257 & $0.4551 * * *$ & 0.0663 & 0.0521 & 0.0122 & -0.0201 \\
& $(4.8266)$ & $(1.2791)$ & $(6.2086)$ & $(1.2263)$ & $(0.9975)$ & $(0.2326)$ & $(-0.5262)$ \\
\hline & & &
\end{tabular}

Notes: 'Diff' represents $L-H$ portfolios for $M E$ and $H-L$ portfolios for other variables. The $t$-statistics are in parentheses, and '***,**,*' indicate that the confidence level is significant at $1 \%, 5 \%$, and $10 \%$, respectively.

Columns 3 and 4 in Table 1 report the portfolio returns sorted by Google attention $(G A)$ and Google attention innovation $G A I$, respectively. The average return of the 'Diff $=$ $H-L$ ' portfolio on $G A$ in column 3 is $2.57 \%$ per week with a $t$-statistic of 1.2791 , which is not significant. Hence, there is no significant impact of Google attention on the cross-sections of the expected cryptocurrency portfolio returns. However, the average return of the low $G A I$ portfolio is $-3.49 \%$ per week and the high $G A I$ portfolio is $42.04 \%$ per week. The average return of the long-short portfolio $(H-L$ portfolio) for $G A I$ is $45.51 \%$ per week with a $t$-statistic of 6.2086 , which is significant at the $1 \%$ significance level. Therefore, the expected cryptocurrency returns for the 
cryptocurrencies at time $t+1$ are significantly related to investors' attention innovation, $G A I$, to the cryptocurrencies at week $t$. This provides an empirical basis for the use of $G A I$ instead of $G A$ to construct the network hype factor.

Additionally, Table 1 reports the relationship between the expected returns and other variables, such as liquidity (Liq), reversal return (STR), momentum return (MOM), and the weekly maximum daily return (MAX). However, the statistical results given in columns 4 to 7 of Table 1 show that there is no significant predictive power in the impact of these factors on the cryptocurrency portfolio returns.

Table 2 reports the Fama-MacBeth (Fama and MacBeth, 1973) cross-sectional return regressions of the six variables above. We see that the market capitalisation has a significantly negative relationship with the cross-sections of the cryptocurrency expected returns with a $t$-statsitic of -4.527 . The Google attention innovation $G A I$ is significantly positively related to the cryptocurrency expected returns, and the coefficient is 0.004 with a $t$-statistic of 3.081. The regressions of both variables ME and $G A I$ are significant at the $1 \%$ confidence level. See columns 1 and 2 of Table 2 . The reversal return (STR) has a significantly negative impact on the cross-sections of the expected cryptocurrency returns. See column 5 of Table 2 .

Table 2 The Fama-MacBeth regressions for all cryptocurrencies

\begin{tabular}{lccccccc}
\hline Variables & $(1)$ & $(2)$ & $(3)$ & $(4)$ & $(5)$ & $(6)$ & $(7)$ \\
\hline $\ln (M E)$ & $-0.023^{* * *}$ & & & & & & $-0.018^{* * *}$ \\
& $(-4.527)$ & & & & & & $(-4.360)$ \\
$\Delta G A$ & & $0.004^{* * *}$ & & & & & $0.004^{* * *}$ \\
& & $(3.081)$ & & & & & $(3.028)$ \\
$\operatorname{Liq}$ & & & 0.046 & & & & $0.111^{* * *}$ \\
& & & $(1.658)$ & & & & $(3.201)$ \\
$R_{M A X}$ & & & & 0.000 & & & 0.000 \\
& & & & $(1.417)$ & & & $(0.405)$ \\
$R_{S T R}$ & & & & & $-0.045^{* * *}$ & & $-0.142^{* * *}$ \\
$R_{M O M}$ & & & & & $(-3.065)$ & & $(-5.454)$ \\
& & & & & & 0.004 & 0.003 \\
Int & $0.443^{* * * *}$ & $0.123^{* * *}$ & $0.110^{* * *}$ & $0.120^{* * *}$ & $0.127^{* * *}$ & $0.117^{* * * *}$ & $0.344^{* * *}$ \\
& $(5.131)$ & $(5.654)$ & $(5.218)$ & $(5.462)$ & $(5.541)$ & $(5.453)$ & $(4.994)$ \\
\hline$R^{2}$ & 0.009 & 0.012 & 0.011 & 0.007 & 0.017 & 0.010 & 0.069 \\
\hline
\end{tabular}

Notes: The $t$-statistics are in parentheses, and '***, $* *, *$ ' indicate that the confidence level is significant at $1 \%, 5 \%$, and $10 \%$, respectively.

Columns 3, 4, and 6 in Table 2, the impacts of liquidity (Liq), weekly maximum daily return (MAX), and momentum return (MOM) on the cross-section of the expected returns are weak, and the regressions of these variables are also not significant. These findings are consistent with the results in Table 1.

The significant impact of Google attention innovation $G A I$ on the cross-sections of the cryptocurrency expected returns motivate us to explore whether network hype is an important driver of increasing cryptocurrency prices? In the next section, we examine the driving effect of Google attention innovation $G A I$ on cryptocurrency returns from the time-series perspective. We call this 'network hype effects'. 


\section{Network hype effects and pricing factors}

\subsection{Network hype effects}

According to the discussion in the previous section, we use changes in Google attention $(G A I)$ to measure the degree of network hype. To check the impact of network hype on the cryptocurrency returns, we use the following regression equation to examine the network hype effects of cryptocurrency $i$ for the time-series returns $R_{i, t}(t=1, \ldots, N)$.

$$
R_{i, t+k}=\operatorname{Int}+\theta_{k} \cdot G A I_{t}+\epsilon_{t}, \quad k \geq 1,
$$

where Int is the intercept and $\epsilon_{t}$ is the white noise series. The regression equation above can help us check simply the impact of network hype at week $t$ on the expected cryptocurrency return $i$ at the future week $t+k(k \geq 1)$. Significantly positive $\theta_{k}(k \geq 1)$ indicates the existence of network hype effect. That is to say, network hype at week $t$ has a positive impact on the future return of the cryptocurrency at week $t+k(k \geq 1)$. For simplicity, we consider the cases $k=1,2,3$ and collect ten mainstream cryptocurrencies. Table 3 reports the test results. ${ }^{2}$

Table 3 shows that Google attention innovation $G A I$ at week $t$ has a significantly positive impact on cryptocurrency returns at the future week $t+1$ or $t+2$ for all ten cryptocurrencies and the cryptocurrency market index. For example, $\theta_{1}=0.001$ and $\theta_{2}=0.005$ are positive for Bitcoin with the corresponding $t$-statistic of 3.121 in $\theta_{2}$, which is significant at the $1 \%$ confidence level. This shows that Google attention innovation $G A I$ at week $t$ has a significantly positive relation with Bitcoin returns at week $t+2$. For Ethereum, $\theta_{1}=0.005$ with a $t$-statistic of 2.440 is also significant at the $5 \%$ confidence level. Similar results are found for the remaining eight cryptocurrencies. Interestingly, using the average Google attention innovation $G A I$ of all valid samples as the degree of network hype on the market index of cryptocurrencies, we find that network hype at week $t$ still has a significantly positive impact on the market return of the cryptocurrency index at week $t+1$. See the $\overline{G A I}$ row of Table 3 . To conclude, the network types measured by Google attention innovation $G A I$ have a significant impact on cryptocurrency returns, which helps to explain why cryptocurrencies can still have high returns in the absence of fundamental support.

\subsection{Pricing factors and the pricing model}

Based on the primary results of Tables 1 and 2 and the network hype effects in Table 3, we find that the impacts of the market capitalisations $M E$ and Google attention innovation $G A I$ on the cross-sections of cryptocurrency expected returns are significant. In this section, we construct the pricing factors based on the three variables $R_{M K T}$, $M E$, and $G A I$ and establish the pricing model for the cryptocurrency market.

To understand the features of the three variables, we plot the monthly average time series trends of the three variables for all cryptocurrencies before constructing the pricing factors. See Figure 1. The return on the cryptocurrency market $R_{m}$ was relatively stable before 2017 but began to oscillate after 2017. Particularly, in April and May of 2017 and 2018, the volatilities of $R_{m}$ were greater than in other months. The reason that the oscillation becomes more pronounced after 2017 could be that the total market value rose rapidly and reached $\$ 81$ billion at the beginning of 2018 then plunged 
to $\$ 34$ billion within six months. This is not surprising. As we have seen, the price of Bitcoin reached $\$ 20,089$ on 17 December 2017, which was the highest point in history, and then fell rapidly within six months. Correspondingly, Google attention innovation $G A I$ shows greater fluctuation after 2017, and the highest point is reached at the end of 2017. From intuitive observation of Figure 1, GAI is nearly completely consistent with the market return and market size of the cryptocurrencies, and the volatilities of $R_{m}$ and $M E$ are also highly consistent with the Google attention innovation $G A I$ volatility.

Table 3 Network hype effects for ten cryptocurrencies

\begin{tabular}{|c|c|c|c|c|c|c|c|c|}
\hline & Name & $\begin{array}{c}R_{t+1} \\
\text { (1) } \\
\end{array}$ & $\begin{array}{c}R_{t+2} \\
\quad(2) \\
\end{array}$ & $\begin{array}{c}R_{t+3} \\
\text { (3) } \\
\end{array}$ & Name & $\begin{array}{c}R_{t+1} \\
\text { (1) } \\
\end{array}$ & $\begin{array}{c}R_{t+2} \\
\text { (2) } \\
\end{array}$ & $\begin{array}{c}R_{t+3} \\
\text { (3) } \\
\end{array}$ \\
\hline$G A I_{t}$ & Bitcoin & $\begin{array}{c}0.001 \\
(0.060)\end{array}$ & $\begin{array}{c}0.005 * * * \\
(3.121)\end{array}$ & $\begin{array}{c}0.002 \\
(1.221)\end{array}$ & Bytecoin & $\begin{array}{c}0.015^{* * *} \\
(2.775)\end{array}$ & $\begin{array}{c}0.003 \\
(0.527)\end{array}$ & $\begin{array}{c}-0.000 \\
(-0.070)\end{array}$ \\
\hline Int & & $\begin{array}{c}0.032 * * \\
(2.578)\end{array}$ & $\begin{array}{c}0.031 * * * \\
(2.630)\end{array}$ & $\begin{array}{c}0.032 * * \\
(2.566)\end{array}$ & & $\begin{array}{l}0.136^{*} \\
(1.850)\end{array}$ & $\begin{array}{l}0.136^{*} \\
(1.771)\end{array}$ & $\begin{array}{l}0.137^{*} \\
(1.764)\end{array}$ \\
\hline$G A I_{t}$ & Ethereum & $\begin{array}{c}0.005^{* *} \\
(2.440)\end{array}$ & $\begin{array}{l}0.0001 \\
(0.058)\end{array}$ & $\begin{array}{c}0.003 \\
(1.251)\end{array}$ & Decred & $\begin{array}{c}0.005^{* *} \\
(2.026)\end{array}$ & $\begin{array}{c}0.001 \\
(0.088)\end{array}$ & $\begin{array}{c}-0.001 \\
(-0.411)\end{array}$ \\
\hline Int & & $\begin{array}{c}0.050 * * * \\
(2.616)\end{array}$ & $\begin{array}{c}0.052 * * * \\
(2.639)\end{array}$ & $\begin{array}{c}0.053 * * * \\
(2.689)\end{array}$ & & $\begin{array}{c}0.065^{* *} \\
(2.375)\end{array}$ & $\begin{array}{c}0.063 * * \\
(2.255)\end{array}$ & $\begin{array}{c}0.065^{* *} \\
(2.305)\end{array}$ \\
\hline$G A I_{t}$ & Ripple & $\begin{array}{c}0.028 * * * \\
(3.318)\end{array}$ & $\begin{array}{c}0.007 \\
(0.827)\end{array}$ & $\begin{array}{c}0.011 \\
(1.247)\end{array}$ & Factom & $\begin{array}{c}0.005^{* * *} \\
(2.902)\end{array}$ & $\begin{array}{l}0.003^{*} \\
(1.934)\end{array}$ & $\begin{array}{c}0.002 \\
(1.199)\end{array}$ \\
\hline Int & & $\begin{array}{l}0.107^{*} \\
(1.905)\end{array}$ & $\begin{array}{l}0.108^{*} \\
(1.824)\end{array}$ & $\begin{array}{l}0.109^{*} \\
(1.829)\end{array}$ & & $\begin{array}{c}0.040 * * \\
(2.027)\end{array}$ & $\begin{array}{c}0.037^{*} \\
(1.846)\end{array}$ & $\begin{array}{l}0.037^{*} \\
(1.803)\end{array}$ \\
\hline$G A I_{t}$ & Monero & $\begin{array}{c}0.016^{* * *} \\
(3.420)\end{array}$ & $\begin{array}{c}0.004 \\
(0.887)\end{array}$ & $\begin{array}{c}0.004 \\
(0.845)\end{array}$ & Litecoin & $\begin{array}{c}0.013 * * * \\
(6.637)\end{array}$ & $\begin{array}{c}0.002 \\
(0.780)\end{array}$ & $\begin{array}{c}-0.000 \\
(-0.087)\end{array}$ \\
\hline Int & & $\begin{array}{c}0.073 * * \\
(2.362)\end{array}$ & $\begin{array}{c}0.073^{* *} \\
(2.227)\end{array}$ & $\begin{array}{c}0.073^{* *} \\
(2.192)\end{array}$ & & $\begin{array}{c}0.044 * * * \\
(2.610)\end{array}$ & $\begin{array}{c}0.045^{* *} \\
(2.193)\end{array}$ & $\begin{array}{c}0.045^{* *} \\
(2.206)\end{array}$ \\
\hline$G A I_{t}$ & BitShares & $\begin{array}{c}0.021 * * * \\
(6.011)\end{array}$ & $\begin{array}{c}0.004 \\
(0.918)\end{array}$ & $\begin{array}{c}0.004 \\
(0.942)\end{array}$ & Maidsafecoin & $\begin{array}{c}0.004 * * * \\
(2.967)\end{array}$ & $\begin{array}{c}0.004 * * * \\
(3.028)\end{array}$ & $\begin{array}{c}0.003 * * \\
(2.084)\end{array}$ \\
\hline Int & & $\begin{array}{c}0.085^{* *} \\
(2.545)\end{array}$ & $\begin{array}{c}0.086^{* *} \\
(2.204)\end{array}$ & $\begin{array}{c}0.086^{* *} \\
(2.193)\end{array}$ & & $\begin{array}{l}0.030^{* *} \\
(1.998)\end{array}$ & $\begin{array}{c}0.031^{* *} \\
(2.042)\end{array}$ & $\begin{array}{c}0.032 * * \\
(2.025)\end{array}$ \\
\hline$\overline{G A I}$ & Crypto_in & $\begin{array}{c}0.024 * * * \\
(4.201)\end{array}$ & $\begin{array}{c}0.002 \\
(0.388)\end{array}$ & $\begin{array}{c}0.014 * * \\
(2.207)\end{array}$ & & & & \\
\hline Int & & $\begin{array}{c}0.034 * * * \\
(2.774)\end{array}$ & $\begin{array}{c}0.035^{* * *} \\
(2.658)\end{array}$ & $\begin{array}{c}0.035 * * * \\
(2.686)\end{array}$ & & & & \\
\hline
\end{tabular}

Notes: The $t$-statistics are in parentheses, and '***, **, *' indicate that the confidence level is significant at $1 \%, 5 \%$, and $10 \%$, respectively. Here, 'Crypto_in' is the cryptocurrency index composed of all samples.

We now construct the pricing factors following the method of Fama and French (1992) in the remainder of this section. To construct the excess returns for the market index, we establish the value-weighted portfolio composed of all of the cryptocurrency samples and then calculate the excess return of the portfolio as the excess return of the cryptocurrency market index:

$$
R_{\mathrm{MKT}, t}=R_{m, t}-r_{f, t},
$$


where $R_{m, t}$ is the average return on the market portfolio at week $t$ and $r_{f, t}$ is the risk-free return at week $t .^{3}$

Figure 1 Dynamic trends of the mean value $(\mu)$ and volatility $(\sigma)$ of the average monthly market return $\left(R_{m}\right)$, average market size $(\mathrm{ME})$, and the average Google attention innovation $(G A I)$ of cryptocurrencies
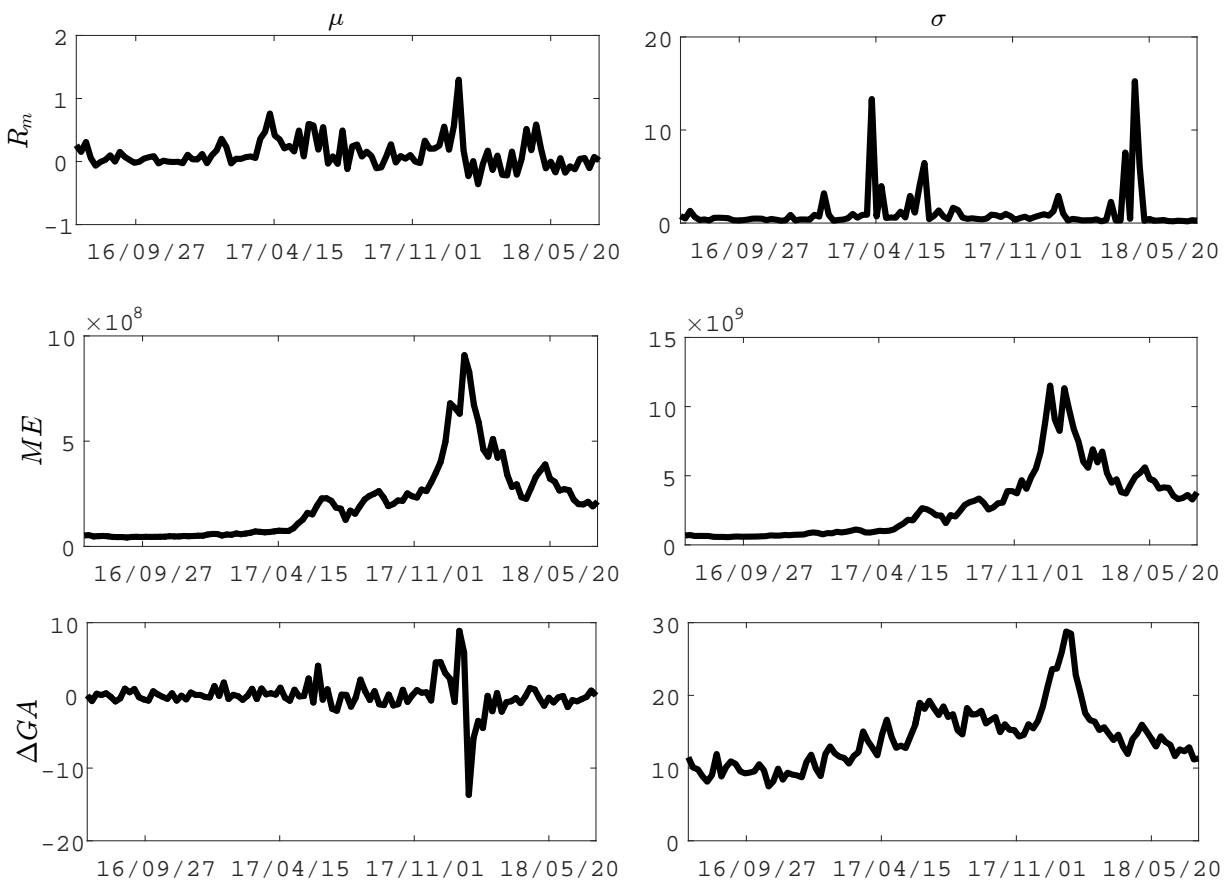

Table 4 The $2 * 3$-factor construction method

\begin{tabular}{lccc}
\hline \multirow{2}{*}{$M E$} & \multicolumn{4}{c}{$G A I$} \\
\cline { 2 - 4 } & $30 \%(L)$ & $40 \%(M)$ & $30 \%(H)$ \\
\hline $50 \%(\mathrm{~S})$ & $\mathrm{SL}$ & $\mathrm{SM}$ & $\mathrm{SH}$ \\
$50 \%(\mathrm{~B})$ & $\mathrm{BL}$ & $\mathrm{BM}$ & $\mathrm{BH}$ \\
\hline
\end{tabular}

We next state the construction of the size factor and the network hype factor. We divide all cryptocurrencies into two groups by their market value: the small-size cryptocurrencies (S) and the big-size cryptocurrencies (B) with the median market cap as the breakpoint. Then, we divide each size group into the low degree of network hype group (L), the medium degree group (M), and the high degree group $(\mathrm{H})$ according to their network hype of Google attention innovation $G A I$, and the breakpoints are the 30th and 70th percentiles of Google attention innovation $G A I$ for all samples. Table 4 gives the $2 * 3$-factor construction method $^{4}$, and we obtain $2 * 3=6$ value-weighted portfolios. Then, the size factor is constructed using the average for the three small-size portfolios minus the average return of the three large-size portfolios: 


$$
R_{M E}=\left(R_{S L}+R_{S M}+R_{S H}\right) / 3-\left(R_{B L}+R_{B M}+R_{B H}\right) / 3 .
$$

Correspondingly, the network hype factor is the average returns for two high network hype portfolios minus the average returns for two low network hype portfolios:

$$
R_{G A I}=\left(R_{S H}+R_{B H}\right) / 2-\left(R_{S L}+R_{B L)} / 2 .\right.
$$

Table 5 gives the statistical characteristics and the corrections for the market factor $R_{M K T}$, size factor $R_{M E}$, and the network hype factor $R_{G A I}$ for the $2 * 3$ - and $2 *$ 2 -factor construction methods including the mean, maximum, minimum, and standard deviation (SD) of these factors and the $t$-statistics for the average returns.

\begin{tabular}{|c|c|c|c|c|c|c|c|c|}
\hline & \multirow{2}{*}{ Mean } & \multirow{2}{*}{$\operatorname{Max}$} & \multirow{2}{*}{ Min } & \multirow{2}{*}{$S D$} & \multirow{2}{*}{$t$-stat } & \multicolumn{3}{|c|}{ Correlations } \\
\hline & & & & & & $R_{M K T}$ & $R_{M E}$ & $R_{G A I}$ \\
\hline \multicolumn{9}{|c|}{ Panel A: $2 * 3$ factors } \\
\hline$R_{M K T}$ & 0.0357 & 0.4312 & -0.3404 & 0.1363 & 2.7024 & 1 & & \\
\hline$R_{M E}$ & 0.1062 & 1.9296 & -0.3070 & 0.2520 & 4.3679 & 0.0560 & 1 & \\
\hline$R_{G A I}$ & 0.0819 & 1.0995 & -1.8258 & 0.2531 & 3.3517 & 0.1501 & -0.1941 & 1 \\
\hline \multicolumn{9}{|c|}{ Panel B: $2 * 2$ factors } \\
\hline$R_{M K T}$ & 0.0357 & 0.4312 & -0.3404 & 0.1363 & 2.7024 & 1 & & \\
\hline$R_{M E}$ & 0.0942 & 1.1018 & -0.5066 & 0.2406 & 4.0564 & 0.0030 & 1 & \\
\hline$R_{G A I}$ & 0.0848 & 1.1712 & -0.9755 & 0.2283 & 3.8472 & 0.0971 & 0.3751 & 1 \\
\hline
\end{tabular}

Table 5 The statistical characteristics and the corrections for the three factors

Notes: ' $t$-stat' is the $t$-statistics for the average returns.

Table 5 shows that the average returns for each factor with the two different construction methods are close. For example, $R_{M E}$ in the $2 * 3$ construction method has a mean value of 0.1062 while the mean value is 0.0942 in the $2 * 2$ construction method. The returns for both $R_{M E}$ 's are close. The $t$-statistics of the average values for both factor construction methods are significant at the $1 \%$ level. However, the factor correlations have obvious differences under the different factor construction methods. As shown in Table 5, the correlation between the market factor $R_{M K T}$ and the Google attention innovation factor $R_{G A I}$ is 0.1501 for the $2 * 3$ construction method while the correlation drops to 0.0971 in the $2 * 2$ method. The change is similar for the correlation between $R_{M K T}$ and $R_{M E}$. Surprisingly, $R_{M E}$ is negatively related with $R_{G A I}$ with a correlation of -0.1941 for the $2 * 3$-factor approach, but the correlation becomes 0.3751 and is positive for the $2 * 2$-factor approach. From the perspective of the factor correlations, both $2 * 3$ and $2 * 2$ construction factor methods can have some influence on the performance of the pricing model. Therefore, in the remainder of the paper, we always consider the empirical results with $2 * 3$ - and $2 * 2$-factor construction methods.

In summary, our three-factor pricing model for the cryptocurrency market can be expressed as follows (week $t$ is omitted):

$$
E\left[R^{i}\right]-r_{f}=\alpha^{i}+\beta_{M K T}^{i} E\left[R_{M K T}\right]+\beta_{M E}^{i} E\left[R_{M E}^{i}\right]+\beta_{G A I}^{i} E\left[R_{G A I}^{i}\right],
$$

where $R^{i}$ is the value-weighted returns for cryptocurrency (portfolio) $i . \beta_{M K T}^{i}, \beta_{M E}^{i}$, and $\beta_{G A I}^{i}$ are the factor loads of $R_{M K T}, R_{M E}^{i}$, and $R_{G A I}^{i}$, respectively. $H_{0}$ hypothesis 
of the pricing model (3) is $\alpha^{i}=0$ for all $i$, which shows that the pricing model is efficient. Our three-factor model is different from the Fama-French three-factor model because the $\mathrm{B} / \mathrm{M}$ is replaced by Google attention innovation $G A I$. In Section 5, we examine the validity and performance of the pricing model (3).

\section{Portfolio construction}

To verify the pricing power of the proposed three-factor model, we divide all cryptocurrency samples into $5 * 5=25$ portfolios according to size $M E$ and Google attention innovation $G A I$. Specifically, at each week $t(t=1,2, \ldots)$, we first sort all the cryptocurrency samples based on their size $M E$ and divide them into five groups with an equal number of cryptocurrencies in each group. We label them as small, 2, 3, 4, and big. Each group of cryptocurrencies is divided continuously into five small groups based on the sorting of Google attention innovation $G A I$ : low, 2, 3, 4, to high. Then, we can form totally $5 * 5=25$ portfolios based on the double-sorting of $M E$ and $G A I$. We calculate the average return for each portfolio, and Table 6 reports the numerical results.

Table 6 The $5 * 5=25$ portfolio returns based on the double-sorting of size $(M E)$ and Google attention innovation $(G A I)$

\begin{tabular}{|c|c|c|c|c|c|c|c|c|c|c|c|c|}
\hline \multirow{2}{*}{$G A I \rightarrow$} & \multicolumn{6}{|c|}{ Average return } & \multicolumn{6}{|c|}{$t$-stat } \\
\hline & Low & 2 & 3 & 4 & High & $H-L$ & Low & 2 & 3 & 4 & High & $H-L$ \\
\hline Small & 0.14 & 0.10 & 0.19 & 0.18 & 0.30 & 0.16 & 3.62 & 3.41 & 3.69 & 3.09 & 4.63 & 2.38 \\
\hline 2 & 0.33 & 0.07 & 0.11 & 0.11 & 0.42 & 0.29 & 1.09 & 2.79 & 5.11 & 3.87 & 2.63 & 0.27 \\
\hline 3 & 0.06 & 0.05 & 0.09 & 0.11 & 0.32 & 0.26 & 2.45 & 2.26 & 4.01 & 4.70 & 3.35 & 2.82 \\
\hline 4 & 0.01 & 0.01 & 0.08 & 0.10 & 0.16 & 0.15 & 0.30 & 0.84 & 3.64 & 3.87 & 4.94 & 5.18 \\
\hline Big & -0.03 & 0.01 & 0.04 & 0.09 & 0.20 & 0.22 & -1.64 & 0.31 & 2.46 & 3.96 & 3.89 & 4.51 \\
\hline
\end{tabular}

Table 6 shows that most of the returns for portfolios increase as the Google attention innovation $G A I$ increases when the size is controlled. For example, the small size low, $H-L$ portfolio constructed by buying high- $G A I$ and selling low- $G A I$ portfolio has a positive excess return of 0.16 per week with a $t$-statistic of 2.38 , which is significant at the $5 \%$ level. We find similar results for the 3 th, 4 th, and the big size lows. These results are expected and not surprising, and they are consistent with the results for the network-type effects in the previous section.

The results in Table 6 indicate that the effects of Google attention innovation $G A I$ on the cryptocurrency portfolio returns are significant even though the sizes of the cryptocurrencies are controlled. In the next section, we regress 25 portfolio returns using our three-factor model (3) to test the ability of the three-factor model to explain excess cryptocurrency returns.

\section{Regression results}

This section mainly analyses the regression results of the three-factor model (3) in the cryptocurrency market. Since our three-factor model is the first pricing model for the 
cryptocurrency market and to illustrate the performance of the proposed three-factor model, we compare the three-factor model (3) with the following CAPM model:

$$
E\left[R^{i}\right]-r_{f}=\alpha^{i}+\beta_{1}^{i} E\left[R_{M K T}\right],
$$

where $R_{M K T}$ is the cryptocurrency market risk factor. Tables 7 and 8 show the regression results for the $5 * 5$ portfolios based on the cross-sorting of ME and Google attention innovation $G A I$ in the previous section. Table 7 reports the results based on the $2 * 3$-factor construction method, and Table 8 reports the results based on the $2 *$ 2 -factor construction method.

Table 7 The regression results for the $5 * 5$ portfolios with double-sorting of ME and Google attention innovation $G A I$

\begin{tabular}{|c|c|c|c|c|c|c|c|c|c|c|}
\hline$G A I \rightarrow$ & Low & 2 & 3 & 4 & High & Low & 2 & 3 & 4 & High \\
\hline \multicolumn{11}{|c|}{ Panel A: $\left(R_{p}-r_{f}\right)=\alpha+\beta_{1} R_{M K T}$} \\
\hline & \multicolumn{5}{|c|}{$\alpha$} & \multicolumn{5}{|c|}{$t(\alpha)$} \\
\hline Small & 0.10 & 0.06 & 0.15 & 0.14 & 0.24 & 2.75 & 2.30 & 2.89 & 2.40 & 3.80 \\
\hline 2 & 0.30 & 0.04 & 0.08 & 0.07 & 0.40 & 0.97 & 1.55 & 4.21 & 2.78 & 2.44 \\
\hline 3 & 0.02 & 0.01 & 0.05 & 0.06 & 0.27 & 0.93 & 0.45 & 2.85 & 3.82 & 2.79 \\
\hline 4 & -0.03 & -0.02 & 0.03 & 0.05 & 0.11 & -1.84 & -2.46 & 2.36 & 2.67 & 3.99 \\
\hline Big & -0.06 & -0.04 & -0.00 & 0.05 & 0.13 & -4.25 & -1.39 & 0.11 & 2.80 & 2.87 \\
\hline \multicolumn{11}{|c|}{ Panel B: $\left(R_{p}-r_{f}\right)=\alpha+\beta_{1} R_{M K T}+\beta_{2} R_{M E}+\beta_{3} R_{G A I}$} \\
\hline & \multicolumn{5}{|c|}{$\alpha$} & \multicolumn{5}{|c|}{$t(\alpha)$} \\
\hline Small & 0.04 & -0.02 & 0.04 & 0.06 & 0.12 & 0.98 & -0.57 & 0.76 & 0.88 & 1.82 \\
\hline 2 & 0.10 & -0.03 & 0.02 & 0.00 & 0.10 & 0.69 & -1.22 & 1.08 & 0.09 & 0.58 \\
\hline 3 & -0.00 & -0.03 & -0.01 & 0.02 & -0.09 & -0.03 & -1.93 & -0.61 & 1.10 & -1.11 \\
\hline 4 & -0.04 & -0.03 & 0.01 & -0.01 & 0.04 & -2.21 & -3.03 & 0.73 & -0.48 & 1.49 \\
\hline \multirow[t]{2}{*}{ Big } & -0.04 & -0.02 & -0.00 & 0.03 & 0.12 & -3.02 & -0.69 & -0.40 & 1.50 & 2.18 \\
\hline & \multicolumn{5}{|c|}{$\beta_{1}$} & \multicolumn{5}{|c|}{$t\left(\beta_{1}\right)$} \\
\hline Small & 0.89 & 0.97 & 1.05 & 0.91 & 1.45 & 3.48 & 5.82 & 2.99 & 2.25 & 3.34 \\
\hline 2 & 2.01 & 0.93 & 0.90 & 1.00 & -0.26 & 2.28 & 6.50 & 8.39 & 6.53 & -0.23 \\
\hline 3 & 1.04 & 1.03 & 1.12 & 1.18 & 0.54 & 7.96 & 10.89 & 11.17 & 11.09 & 1.06 \\
\hline 4 & 0.87 & 0.99 & 1.25 & 1.24 & 1.17 & 8.55 & 15.27 & 13.24 & 11.1 & 6.32 \\
\hline \multirow[t]{2}{*}{ Big } & 0.84 & 1.30 & 1.02 & 1.25 & 1.73 & 9.08 & 6.97 & 19.96 & 10.94 & 5.08 \\
\hline & \multicolumn{5}{|c|}{$\beta_{2}$} & \multicolumn{5}{|c|}{$t\left(\beta_{2}\right)$} \\
\hline Small & 0.43 & 0.55 & 0.69 & 0.44 & 0.73 & 3.05 & 6.04 & 3.60 & 1.99 & 3.08 \\
\hline 2 & 7.21 & 0.45 & 0.37 & 0.51 & 1.66 & 15.04 & 5.74 & 6.40 & 6.11 & 2.69 \\
\hline 3 & 0.08 & 0.25 & 0.37 & 0.26 & 1.94 & 1.17 & 4.90 & 6.83 & 4.43 & 6.93 \\
\hline 4 & 0.08 & 0.07 & 0.15 & 0.33 & 0.43 & 1.41 & 2.00 & 2.92 & 5.34 & 4.29 \\
\hline \multirow[t]{2}{*}{ Big } & -0.03 & -0.11 & -0.00 & 0.07 & 0.12 & -0.54 & -1.10 & -0.02 & 1.11 & 0.64 \\
\hline & \multicolumn{5}{|c|}{$\beta_{3}$} & \multicolumn{5}{|c|}{$t\left(\beta_{3}\right)$} \\
\hline Small & 0.26 & 0.29 & 0.52 & 0.51 & 0.56 & 1.83 & 3.18 & 2.70 & 2.31 & 2.37 \\
\hline 2 & -7.43 & 0.23 & 0.26 & 0.19 & 1.77 & -15.4 & 2.97 & 4.48 & 2.31 & 2.86 \\
\hline 3 & 0.13 & 0.13 & 0.29 & 0.27 & 2.21 & 1.78 & 2.52 & 5.34 & 4.66 & 7.87 \\
\hline 4 & 0.02 & 0.02 & 0.08 & 0.35 & 0.35 & 0.33 & 0.57 & 1.53 & 5.68 & 3.41 \\
\hline Big & -0.12 & -0.06 & 0.06 & 0.16 & 0.08 & -2.36 & -0.56 & 2.00 & 2.52 & 0.41 \\
\hline
\end{tabular}

Notes: The pricing factors are calculated by the $2 * 3$-factor construction approach. 
Table 8 The regression results for the $5 * 5$ portfolios with double-sorting of ME and Google attention innovation $G A I$

\begin{tabular}{|c|c|c|c|c|c|c|c|c|c|c|}
\hline GAI & Low & 2 & 3 & 4 & High & Low & 2 & 3 & 4 & High \\
\hline \multicolumn{11}{|c|}{ Panel A: $\left(R_{p}-r_{f}\right)=\alpha+\beta_{1} R_{M K T}$} \\
\hline & \multicolumn{5}{|c|}{$\alpha$} & \multicolumn{5}{|c|}{$t(\alpha)$} \\
\hline Small & 0.10 & 0.06 & 0.15 & 0.14 & 0.24 & 2.75 & 2.30 & 2.89 & 2.40 & 3.80 \\
\hline 2 & 0.30 & 0.04 & 0.08 & 0.07 & 0.40 & 0.97 & 1.55 & 4.21 & 2.78 & 2.44 \\
\hline 3 & 0.02 & 0.01 & 0.05 & 0.06 & 0.27 & 0.93 & 0.45 & 2.85 & 3.82 & 2.79 \\
\hline 4 & -0.03 & -0.02 & 0.03 & 0.05 & 0.11 & -1.84 & -2.46 & 2.36 & 2.67 & 3.99 \\
\hline Big & -0.06 & -0.04 & 0.00 & 0.05 & 0.13 & -4.25 & -1.39 & 0.11 & 2.80 & 2.87 \\
\hline \multicolumn{11}{|c|}{ Panel B: $\left(R_{p}-r_{f}\right)=\alpha+\beta_{1} R_{M K T}+\beta_{2} R_{M E}+\beta_{3} R_{G A I}$} \\
\hline & \multicolumn{5}{|c|}{$\alpha$} & \multicolumn{5}{|c|}{$t(\alpha)$} \\
\hline Small & 0.04 & 0.01 & 0.09 & 0.08 & 0.17 & 1.10 & 0.33 & 1.66 & 1.24 & 2.54 \\
\hline 2 & 0.25 & 0.00 & 0.04 & 0.03 & -0.02 & 1.10 & -0.17 & 2.22 & 1.02 & -0.13 \\
\hline 3 & 0.00 & -0.02 & 0.01 & 0.03 & -0.01 & 0.09 & -1.17 & 0.68 & 1.71 & -0.09 \\
\hline 4 & -0.04 & -0.03 & 0.02 & 0.01 & 0.06 & -2.54 & -3.10 & 1.32 & 0.68 & 2.15 \\
\hline Big & -0.05 & -0.03 & -0.00 & 0.03 & 0.12 & -3.73 & -1.12 & -0.34 & 1.56 & 2.49 \\
\hline & \multicolumn{5}{|c|}{$\beta_{1}$} & \multicolumn{5}{|c|}{$t\left(\beta_{1}\right)$} \\
\hline Small & 0.92 & 1.09 & 1.25 & 1.03 & 1.67 & 3.76 & 6.36 & 3.49 & 2.58 & 3.81 \\
\hline 2 & 2.15 & 1.05 & 0.99 & 1.08 & -0.02 & 1.42 & 7.23 & 8.64 & 6.65 & -0.02 \\
\hline 3 & 1.06 & 1.09 & 1.22 & 1.24 & 1.11 & 8.23 & 11.45 & 11.21 & 11.79 & 2.08 \\
\hline 4 & 0.88 & 1.00 & 1.29 & 1.34 & 1.29 & 8.97 & 15.82 & 13.6 & 11.13 & 6.98 \\
\hline Big & 0.82 & 1.27 & 1.03 & 1.26 & 1.67 & 8.73 & 6.84 & 20.16 & 11.59 & 5.13 \\
\hline & \multicolumn{5}{|c|}{$\beta_{2}$} & \multicolumn{5}{|c|}{$t\left(\beta_{2}\right)$} \\
\hline Small & 0.21 & 0.49 & 0.60 & 0.36 & 0.70 & 1.40 & 4.66 & 2.74 & 1.47 & 2.61 \\
\hline 2 & 8.24 & 0.47 & 0.29 & 0.34 & 2.35 & 8.98 & 5.28 & 4.20 & 3.41 & 3.98 \\
\hline 3 & 0.05 & 0.25 & 0.30 & 0.22 & 1.72 & 0.59 & 4.34 & 4.51 & 3.50 & 5.29 \\
\hline 4 & 0.15 & 0.10 & 0.14 & 0.25 & 0.45 & 2.43 & 2.48 & 2.43 & 3.40 & 3.97 \\
\hline Big & 0.04 & -0.06 & -0.01 & -0.02 & -0.34 & 0.64 & -0.57 & -0.28 & -0.29 & -1.72 \\
\hline & \multicolumn{5}{|c|}{$\beta_{3}$} & \multicolumn{5}{|c|}{$t\left(\beta_{3}\right)$} \\
\hline Small & 0.52 & 0.10 & 0.04 & 0.35 & 0.07 & 3.29 & 0.91 & 0.16 & 1.36 & 0.24 \\
\hline 2 & -9.22 & -0.06 & 0.12 & 0.14 & 2.55 & -9.48 & -0.65 & 1.58 & 1.37 & 4.08 \\
\hline 3 & 0.14 & 0.00 & 0.13 & 0.20 & 1.46 & 1.66 & 0.50 & 1.91 & 2.88 & 4.24 \\
\hline 4 & -0.02 & -0.02 & -0.00 & 0.18 & 0.13 & -0.29 & -0.38 & -0.05 & 2.28 & 1.13 \\
\hline Big & -0.07 & 0.03 & 0.05 & 0.27 & 0.54 & -1.20 & 0.21 & 1.64 & 3.88 & 2.58 \\
\hline
\end{tabular}

Notes: The pricing factors are calculated by the $2 * 2$-factor construction approach.

Panel A of Tables 7 and 8 show the regression results for CAPM, and panel B of both Tables 7 and 8 report the empirical results of our three-factor model. Note our $H_{0}$ hypothesis: $\alpha=0$. Thus, it is valuable to compare the number of the nonzero alphas in the two models. We find from panel A of both tables that there are 19 alphas that differ significantly from zero in the 25 excess returns for the CAPM model under the $10 \%$ confidence level. The number of nonzero alphas decreases to 18 under the $5 \%$ 
confidence level and decreases continuously to 13 under the $1 \%$ confidence level, which is more than the half of 25 . Therefore, CAPM is completely not effective in explaining excess cryptocurrency returns.

However, these cases are improved when we look at panel B of Tables 7 and 8 . The number of nonzero alphas is only six (see panel B of Table 7) and eight (see panel B of Table 8 ) under the $10 \%$ significance level, which is less than one-third of the total 25 portfolios. The number of nonzero alphas is reduced to two with $t \geq 2.58$ (see panel $\mathrm{B}$ of both Tables 7 and 8) when the confidence level is set to $1 \%$, respectively. The number of nonzero alphas in the proposed three-factor model is far less than CAPM. In the $2 * 3$-factor approach, there are only two nonzero alphas in all 25 portfolios under the $1 \%$ confidence level. This is almost consistent with the $H_{0}$ hypothesis. This result shows that our three-factor model can explain excess cryptocurrency returns, and its performance is better than the case where we consider the market factor alone.

The impact of the market factor on the cryptocurrency returns is significantly positive. 24 out of the $25 \beta_{1}$ 's are positive, and $23 t$-statistics of $\beta_{1}$ are greater than 1.96 in Table 7. Thus, the market factor is positively correlated with the excess cryptocurrency returns. This is consistent with our expectation because in the relation between return and risk, high market risk is expected to obtain high-risk compensation.

In the slopes of $R_{M E}$ from Table 7, 22 out of $25 \beta_{2}$ 's are positive, and $18 t$-statistics are greater than 1.96. These results are consistent with our expectations. Most of the significantly positive $\beta_{2}$ 's indicate a negative correlation between the asset size and the excess return. The larger the size of the asset, the harder it is to obtain excess cryptocurrency returns. This is consistent with equity markets. But the reason may differ from the equity markets, where The main objects for shareholders are to obtain stock dividends. In addition to obtain the capital growth gain, however, many cryptocurrency holders have another object that they transfer their capital from one market to another (Vlastelica, 2017). The special functions of cryptocurrencies of a relatively large size will attract regulator attention. On the one hand, a cryptocurrency with a large market value can attract more traders globally and, therefore, it could be more convenient to transfer these cryptocurrency assets. On the other hand, it can be more difficult for traders to transfer their assets using cryptocurrencies with a large market value because regulators pay close attention to these high value cryptocurrencies. To avoid regulation, the latter dominates the former. Hence, demand may decrease for large-scale cryptocurrencies along with their returns. In contrast, small-scale cryptocurrencies are seldom under the microscope of regulators and may be more attractive for traders who want to transfer their assets. This can lead to higher cryptocurrency returns.

We now analyse the impact of Google attention innovation $G A I$ on cryptocurrency returns. We find that there are 22 positive $\beta_{3}$ 's in the 25 portfolios and $18 t$-statistics are significant at the $10 \%$ confidence level from Table 7 . Thus, the network hype factor measured by Google attention innovation $G A I$ has a significantly positive impact on cryptocurrency returns. The reason is that many investors have little understanding of the cryptocurrency market and are merely following the market. Such followers are usually affected by the market information from the network hype and choose to invest in cryptocurrencies based on a high level of attention to the network. When the cryptocurrency returns rise, the high returns can attract more attention causing additional investment. This generates a cycle whereby more attention can lead to more investments, and in turn, lead to more attention, and so on. 
We find similar results in Table 8 for the impact of $R_{M K E}, R_{M E}$, and $R_{G A I}$ on cryptocurrency returns and, therefore, the empirical results are nearly consistent for the 2 * 3- and $2 * 2$-factor construction approaches. We close this section with some remarks on the empirical results in Tables 7 and 8 . The proposed three-factor pricing model, in general, has superior pricing power than the CAPM from the number of nonzero alphas. The size effect exists and is consistent with the stock market, but the reasons are different from the stock market. The network hype effect exists in the cryptocurrency market and is positively related to the cryptocurrency returns. These results can partially explain why cryptocurrency prices can rise without the support of the fundamentals.

\section{The performance of the pricing model}

In the previous sections, we have known that the three-factor model has good explanatory power for excess cryptocurrency returns. In this section, we further examine the performance of the pricing model in three ways. First, we construct liquidity, reversal, and momentum factors and then check the explanatory power of the proposed three-factor model for the three new factors using the linear regression method. Second, we use the GRS method to test the performance of the proposed three-factor model when we add a new factor to the three-factor model. Finally, we use the three-factor model to explain two excess return anomalies in the small size samples.

Table 9 The regressions of all factors

\begin{tabular}{|c|c|c|c|c|c|c|}
\hline & $R_{M K T}$ & $R_{M E}$ & $R_{G A I}$ & $R_{L i q}$ & $R_{S T R}$ & $R_{M O M}$ \\
\hline \multicolumn{7}{|c|}{ Panel A: $2 * 3$ factors } \\
\hline$R_{M K T}$ & & $\begin{array}{c}0.160 \\
(0.903)\end{array}$ & $\begin{array}{l}0.299^{*} \\
(1.708)\end{array}$ & $\begin{array}{c}0.443 * * \\
(1.970)\end{array}$ & $\begin{array}{c}0.146 \\
(0.770)\end{array}$ & $\begin{array}{c}0.207 \\
(1.340)\end{array}$ \\
\hline$R_{M E}$ & $\begin{array}{c}0.048 \\
(0.903)\end{array}$ & & $\begin{array}{c}-0.204 * * \\
(-2.156)\end{array}$ & $\begin{array}{c}0.794 * * * \\
(6.477)\end{array}$ & $\begin{array}{c}0.076 \\
(0.736)\end{array}$ & $\begin{array}{c}0.196^{* *} \\
(2.319)\end{array}$ \\
\hline$R_{G A I}$ & $\begin{array}{l}0.090^{*} \\
(1.708)\end{array}$ & $\begin{array}{c}-0.206^{* *} \\
(-2.156)\end{array}$ & & $\begin{array}{c}-0.397 * * * \\
(-3.220)\end{array}$ & $\begin{array}{c}0.144 \\
(1.386)\end{array}$ & $\begin{array}{c}0.253 * * * \\
(2.981)\end{array}$ \\
\hline $\ln t$ & $\begin{array}{c}0.023 \\
(1.521)\end{array}$ & $\begin{array}{c}0.117 * * * \\
(4.574)\end{array}$ & $\begin{array}{c}0.093 * * * \\
(3.517)\end{array}$ & $\begin{array}{c}0.006 \\
(0.175)\end{array}$ & $\begin{array}{c}0.014 \\
(0.482)\end{array}$ & $\begin{array}{c}-0.036 \\
(-1.483)\end{array}$ \\
\hline$R^{2}$ & 0.030 & 0.045 & 0.063 & 0.390 & 0.029 & 0.130 \\
\hline \multicolumn{7}{|c|}{ Panel B: $2 * 2$ factors } \\
\hline$R_{M K T}$ & & $\begin{array}{c}-0.059 \\
(-0.371)\end{array}$ & $\begin{array}{c}0.161 \\
(1.073)\end{array}$ & $\begin{array}{c}0.194 \\
(1.573)\end{array}$ & $\begin{array}{c}0.129 \\
(0.871)\end{array}$ & $\begin{array}{c}0.285 * * * \\
(2.648)\end{array}$ \\
\hline$R_{M E}$ & $\begin{array}{l}-0.022 \\
(-0.371)\end{array}$ & & $\begin{array}{c}0.355^{* * *} \\
(4.180)\end{array}$ & $\begin{array}{c}0.301 * * * \\
(4.009)\end{array}$ & $\begin{array}{c}0.398 * * * \\
(4.433)\end{array}$ & $\begin{array}{c}0.410^{* * *} \\
(6.268)\end{array}$ \\
\hline$R_{G A I}$ & $\begin{array}{c}0.067 \\
(1.073)\end{array}$ & $\begin{array}{c}0.398 * * * \\
(4.180)\end{array}$ & & $\begin{array}{c}-0.232 * * * \\
(-2.924)\end{array}$ & $\begin{array}{c}-0.411 * * * \\
(-4.317)\end{array}$ & $\begin{array}{c}-0.334 * * * \\
(-4.823)\end{array}$ \\
\hline $\ln t$ & $\begin{array}{c}0.032 * * \\
(2.197)\end{array}$ & $\begin{array}{c}0.062 * * * \\
(2.648)\end{array}$ & $\begin{array}{l}0.046^{* *} \\
(2.019)\end{array}$ & $\begin{array}{c}0.016 \\
(0.859)\end{array}$ & $\begin{array}{c}0.019 \\
(0.847)\end{array}$ & $\begin{array}{c}0.011 \\
(0.654)\end{array}$ \\
\hline$R^{2}$ & 0.011 & 0.142 & 0.150 & 0.160 & 0.211 & 0.327 \\
\hline
\end{tabular}

Notes: The $t$-statistics are in parentheses, and '***, $* *,{ }^{*}$ ' indicate that the confidence level is significant at $1 \%, 5 \%$, and $10 \%$, respectively. 


\subsection{The risky factor regressions}

Consider the regressions of the liquidity factor (LIQ), reversal factor (STR), and momentum factor (MOM) on the three-factor model:

$$
E\left[R_{\text {factor }}\right]=\operatorname{Int}+\gamma_{1} E\left[R_{M K T}\right]+\gamma_{2} E\left[R_{M E}\right]+\gamma_{3} E\left[R_{G A I}\right]
$$

where $I n t$ is the intercept term, $R_{\text {factor }}$ is one of the factors in $\left(R_{M K T}, R_{M E}, R_{G A I}\right.$, $\left.R_{L I Q}, R_{S T R}, R_{M O M}\right) \cdot \gamma_{1}, \gamma_{2}$, and $\gamma_{3}$ are the risky loads of $R_{M K T}, R_{M E}$, and $R_{G A I}$, respectively. Table 9 shows the results of the regression. Panel A gives the results with the factors calculated using the $2 * 3$-factor construction approach, and panel $\mathrm{B}$ gives the results with the factors calculated using the $2 * 2$-factor construction approach.

All empirical results are as expected. Panel A of Table 9 shows that when $R_{\text {factor }}$ 's are $R_{M E}$ and $R_{G A I}$, the constant terms Int's are 0.117 and 0.093 , and the corresponding $t$-statistics are 4.574 and 3.517 , respectively, which are significant at the $1 \%$ confidence level. Thus, both factors of size and Google attention innovation $G A I$ cannot be explained by each other. However, when $R_{\text {factor }}$ 's are $R_{L I Q}, R_{S T R}$, and $R_{M O M}$, the $t$-statistics of the intercepts in the regressions are not significant. Thus, the three factors can be captured by our three factors: market factor, size factor, and GAI. Similar results can also be found in panel B of Table 9.

\subsection{GRS tests}

To test how well the three-factor model explains the average excess portfolio returns in Table 6, we consider five asset pricing models:

\section{1 the CAPM model}

2 the proposed three-factor model

3 three four-factor models that combine $R_{M K T}, R_{M E}, R_{G A I}$, and $R_{L I Q}, R_{S T R}$, or $R_{M O M}$.

With five models, four sets of left-hand-side (LHS) portfolios and one set of right-hand-side (RHS) factors (see Table 6), it makes sense to restrict our attention to models that fare relatively well in the tests. Four sets of LHS portfolios are $25 \mathrm{ME}-G A I$ portfolios, 25 ME-LIQ portfolios, 25 ME-STR portfolios, and 25 ME-MOM portfolios, respectively. In this subsection, we use the GRS statistic of Gibbons et al. (1989) to test this hypothesis for combinations of LHS portfolios and factors and show how well the three-factor model explains the average excess cryptocurrency returns.

If an asset pricing model completely captures the expected returns, the intercept is indistinguishable from zero in a regression of an asset's excess return on the model's factor. Then, the joint tests of the intercept terms of all 25 regressions should not reject the null hypothesis of $\alpha=0$. A small GRS value shows that the reason the pricing model cannot reject the zero-constant term is more sufficient. In other words, the smaller the value of the GRS, the better the pricing model. See Table 10 for the GRS test results.

Table 10 shows an additional three indicators: $A\left(\left|\alpha_{i}\right|\right), \frac{A\left(\left|\alpha_{i}\right|\right)}{A\left(\left|\bar{r}_{i}\right|\right)}$ and $\frac{A\left(\widehat{\alpha}_{i}^{2}\right)}{A\left(\left(\hat{\mu}_{i}^{2}\right)\right)} \cdot A\left(\left|\alpha_{i}\right|\right)$ represents the average of the absolute values of the intercept terms of the regressions for the set of LHS with 25 portfolios. $\frac{A\left(\left|\alpha_{i}\right|\right)}{A\left(\left|\bar{r}_{i}\right|\right)}$ represents the proportion of the actual 
cryptocurrency portfolio returns that cannot be accounted for by the model interpretation part where $r_{i}$ is defined as the deviation of portfolio $i$ from the cross-section average, that is, $r_{i}=R_{i}-\bar{R}$, and $A\left(\left|\bar{r}_{i}\right|\right)$ are the average absolute values of $\bar{r}_{i}$ for 25 portfolios. $\frac{A\left(\widehat{\alpha}_{i}^{2}\right)}{A\left(\hat{\mu}_{i}^{2}\right)}$ represents the proportion of the returns that cannot be explained by the model in the cryptocurrency portfolio returns in the second-order information, where $A\left(\alpha_{i}^{2}\right)$ is the average squares of the intercept terms of the 25 portfolios, and $A\left(\hat{\mu}_{i}^{2}\right)$ is the average squares of $\bar{r}_{i}$. The above three indicators are similar to the GRS; that is, the smaller the values, the better the model performance.

Table 10 GRS tests for all models

\begin{tabular}{|c|c|c|c|c|c|c|c|c|}
\hline \multirow{2}{*}{ Factors } & \multicolumn{4}{|c|}{$2 * 3$ factors } & \multicolumn{4}{|c|}{$2 * 2$ factors } \\
\hline & $G R S$ & $A\left(\left|\alpha_{i}\right|\right)$ & $\frac{A\left|\alpha_{i}\right|}{A\left(\left|\bar{r}_{i}\right|\right)}$ & $\frac{A\left(\hat{\alpha}_{i}^{2}\right)}{A\left(\hat{\mu}_{i}^{2}\right)}$ & $G R S$ & $A\left(\left|\alpha_{i}\right|\right)$ & $\frac{A\left|\alpha_{i}\right|}{A\left(\left|\bar{r}_{i}\right|\right)}$ & $\frac{A\left(\hat{\alpha}_{i}^{2}\right)}{A\left(\hat{\mu}_{i}^{2}\right)}$ \\
\hline \multicolumn{9}{|c|}{ Panel A: $25 M E-G A I$ portfolios } \\
\hline$R_{M K T}$ & 3.2583 & 0.0998 & 0.5420 & 0.4734 & 3.2583 & 0.0998 & 0.5420 & 0.4734 \\
\hline$R_{M E}, R_{G A I}$ & 2.0173 & 0.0405 & 0.2200 & 0.0701 & 2.3957 & 0.0477 & 0.2591 & 0.1326 \\
\hline$R_{M E}, R_{G A I}, R_{S T R}$ & 2.5572 & 0.0439 & 0.2384 & 0.0860 & 2.3702 & 0.0460 & 0.2498 & 0.0994 \\
\hline$R_{M E}, R_{G A I}, R_{M O M}$ & 2.0729 & 0.0321 & 0.1743 & 0.0488 & 2.3050 & 0.0460 & 0.2498 & 0.1151 \\
\hline$\underline{R}_{M E}, R_{G A I}, R_{L i q}$ & 2.2013 & 0.0413 & 0.2243 & 0.0732 & 2.3306 & 0.0455 & 0.2471 & 0.0929 \\
\hline \multicolumn{9}{|c|}{ Panel B: $25 M E-L I Q$ portfolios } \\
\hline$R_{M K T}$ & 1.8469 & 0.0638 & 0.4962 & 0.4078 & 1.8469 & 0.0638 & 0.4962 & 0.4078 \\
\hline$R_{M E}, R_{G A I}$ & 1.1060 & 0.0233 & 0.1812 & 0.0728 & 1.2355 & 0.0338 & 0.2629 & 0.1844 \\
\hline$R_{M E}, R_{G A I}, R_{S T R}$ & 1.0960 & 0.0228 & 0.1773 & 0.0688 & 1.2447 & 0.0323 & 0.2512 & 0.1472 \\
\hline$R_{M E}, R_{G A I}, R_{M O M}$ & 1.0443 & 0.0245 & 0.1905 & 0.0865 & 1.2544 & 0.0320 & 0.2488 & 0.1629 \\
\hline$R_{M E}, R_{G A I}, R_{L i q}$ & 1.1105 & 0.0230 & 0.1789 & 0.0703 & 1.2584 & 0.0319 & 0.2481 & 0.1380 \\
\hline \multicolumn{9}{|c|}{ Panel C: $25 M E-S T R$ portfolios } \\
\hline$R_{M K T}$ & 3.4639 & 0.0684 & 0.5092 & 0.4615 & 3.4639 & 0.0684 & 0.5092 & 0.4615 \\
\hline$R_{M E}, R_{G A I}$ & 2.1005 & 0.0262 & 0.1950 & 0.0898 & 2.4541 & 0.0408 & 0.3037 & 0.2048 \\
\hline$R_{M E}, R_{G A I}, R_{S T R}$ & 2.0991 & 0.0254 & 0.1891 & 0.0887 & 2.4171 & 0.0394 & 0.2933 & 0.1759 \\
\hline$R_{M E}, R_{G A I}, R_{M O M}$ & 2.1111 & 0.0289 & 0.2151 & 0.0995 & 2.445 & 0.039 & 0.2903 & 0.1846 \\
\hline$R_{M E}, R_{G A I}, R_{L i q}$ & 2.0979 & 0.0258 & 0.1921 & 0.0891 & 2.4407 & 0.0375 & 0.2792 & 0.1655 \\
\hline \multicolumn{9}{|c|}{ Panel D: $25 \mathrm{ME}-$ MOM portfolios } \\
\hline$R_{M K T}$ & 1.4616 & 0.0637 & 0.5086 & 0.3989 & 1.4616 & 0.0637 & 0.5086 & 0.3989 \\
\hline$R_{M E}, R_{G A I}$ & 0.6772 & 0.0193 & 0.1541 & 0.0464 & 0.9406 & 0.0291 & 0.2323 & 0.1244 \\
\hline$R_{M E}, R_{G A I}, R_{S T R}$ & 0.7427 & 0.0208 & 0.1661 & 0.0522 & 0.9159 & 0.0303 & 0.2419 & 0.1070 \\
\hline$R_{M E}, R_{G A I}, R_{M O M}$ & 0.6651 & 0.0171 & 0.1365 & 0.0343 & 0.9330 & 0.0294 & 0.2347 & 0.1135 \\
\hline$R_{M E}, R_{G A I}, R_{L i q}$ & 0.6915 & 0.0197 & 0.1573 & 0.0475 & 0.9074 & 0.0291 & 0.2323 & 0.0974 \\
\hline
\end{tabular}

Table 10 shows that the performance of CAPM is the weakest among all five pricing models because no one of the four indicators for CAPM is the best in all four sets of LHS portfolios. The other four asset pricing models have their own advantages for different indicators. When GRS is used as the judgment, the proposed three-factor model in this paper is such that the three sets of LHS portfolios show the minimum GRS, namely, the ME-GAI portfolios and ME-MOM for the $2 * 3$-factor approach 
and ME-LIQ portfolios for the $2 * 2$-factor approach. The number of minimum GRS is the largest among the five pricing models. For the other three indicators, we find that they are almost consistent; that is, one index is the smallest in a pricing model, and the other two indicators are almost the smallest in the model. For example, the $A\left(\left|\alpha_{i}\right|\right)$ obtained by the three-factor model adding the momentum factor is the smallest, and $A\left(\left|\alpha_{i}\right|\right) / A\left(\left|\bar{r}_{i}\right|\right)$ and $A\left(\alpha_{i}^{2}\right) / A\left(\mu_{i}^{2}\right)$ of this model are also the smallest for ME- $G A I$ portfolios and ME-MOM portfolios in the $2 * 3$-factor construction approach. Therefore, combining Tables 9 and 10, we see that when STR, MOM, or LIQ is added to our three-factor model, the model has some improvement in its cryptocurrency explanatory power, but the improvement is limited. In addition, the three factors, STR, MOM, and LIQ, can be explained by our three-factor model. Therefore, it is appropriate to construct the three-factor model with the market factor, size factor, and network hype factor. In the next subsection, we use the three-factor model to explain two excess return anomalies in the small-size samples. These results further reflect the performance of the proposed three-factor model.

\subsection{Two anomalies of returns}

Table 1 shows that the reversal return and the weekly maximum daily return do not significantly affect the cross-sectional expected cryptocurrency returns under the full samples. However, we find that if the samples are divided into two groups by size, and the small-size group is divided into decile portfolios based on the sorting of $R_{S T R}$ and $R_{M A X}$, the reversal and MAX effects exist at a significant level of 5\%. Table 11 shows that the average return of a long-short portfolio by $R_{M A X}$ is 0.3067 per week in the small-size samples with $t=2.2720$. Similarly, in the decile portfolios sorted by $R_{S T R}$, the average return of a long-short portfolio is 0.2830 per week, and the corresponding $t=2.0369$. We use CAPM and the proposed three-factor model to explain two excess return portfolio anomalies.

The results in Table 11 show that CAPM has a weak ability to explain the anomaly of excess return generated by $M A X$. This is because $\alpha_{C A P M}=0.2736$ and $t=2.1309$, which is still significant under the $5 \%$ confidence level. On the other hand, CAPM has a little explanatory power for the anomaly of excess return caused by the reversal effect because $\alpha_{C A P M}=0.2982$ and $t=1.8991$. This result is significant at the $10 \%$ confidence level.

However, the anomalies of excess returns caused by MAX and STR can be explained completely by our three-factor model. See panel A in Table 11 for MAX. The value of alpha $(\alpha(2 * 3))$ for the three-factor model with the factors calculated using the $2 * 3$-factor method is -0.1336 and the corresponding $t=-1.0222$, which is not significant. Similarly, for the $2 * 2$-factor construction method, $\alpha(2 * 2)=-0.1224$ and the corresponding $t=-1.0892$, which is still not significant. The same result is also obtained for the reversal effect. See panel B in Table 11. These results show that our proposed three-factor model has good explanatory power for the anomalies of excess returns caused by the reversal effect and the weekly maximum daily returns.

We close this section with some remarks. The performance of the proposed three-factor model is checked in three ways. Using the three-factor model in regressions to explain the average returns on the other three factors obtains the expected results. The returns of $R_{L I Q}, R_{S T R}$, or $R_{M O M}$ can be explained completely by the three-factor model. The anomalies of returns caused by MAX and STR can be explained by the 
proposed three-factor model. The only shortcoming is that the proposed three-factor model cannot obtain the best GRS test results, but the improvement is limited when other factors are added to the three-factor model. Thus, the proposed three-factor model is sufficient to explain excess cryptocurrency returns.

Table 11 Two anomalies

\begin{tabular}{lccccccccccc}
\hline Rank & Low & 2 & 3 & 4 & 5 & 6 & 7 & 8 & 9 & High & $H-L$ \\
\hline \multicolumn{8}{c}{ Panel A: portfolios } & sorted on $R_{M A X}$ \\
\hline $\bar{r}$ & 0.0813 & 0.1090 & 0.1065 & 0.1018 & 0.0905 & 0.2628 & 0.1210 & 0.0846 & 0.1457 & 0.3880 & 0.3067 \\
$t(\bar{r})$ & 4.1977 & 5.2061 & 4.1363 & 4.4292 & 3.4491 & 1.7468 & 3.5076 & 3.3986 & 3.9456 & 2.8532 & 2.2720 \\
$\alpha_{C A P M}$ & 0.0483 & 0.0732 & 0.0651 & 0.0639 & 0.0472 & 0.2225 & 0.0917 & 0.0482 & 0.1032 & 0.3468 & 0.2982 \\
$t\left(\alpha_{C A P M}\right)$ & 3.0955 & 4.3461 & 3.0316 & 3.3806 & 2.1907 & 1.433 & 2.7016 & 2.2211 & 2.9788 & 2.4737 & 2.1309 \\
$\alpha_{3}(2 * 3)$ & -0.0022 & 0.0213 & 0.0021 & 0.0081 & -0.0161 & 0.0464 & 0.0140 & -0.0044 & 0.0072 & -0.1355 & -0.1336 \\
$t\left(\alpha_{3}\right)$ & -0.1483 & 1.3380 & 0.1009 & 0.4417 & -0.7647 & 0.7331 & 0.3939 & -0.1971 & 0.2093 & -1.0972 & -1.0222 \\
$\alpha_{3}(2 * 2)$ & 0.0127 & 0.0383 & 0.0235 & 0.0247 & 0.0077 & 0.1583 & 0.0378 & 0.0103 & 0.0368 & -0.1094 & -0.1224 \\
$t\left(\alpha_{3}\right)$ & 0.8717 & 2.3931 & 1.1346 & 1.3416 & 0.3581 & 1.4110 & 1.1001 & 0.4681 & 1.0757 & -1.0482 & -1.0892 \\
\hline \multicolumn{8}{c}{ Panel $B:$ portfolios } & sorted & on & $R_{S T R}$ \\
\hline $\bar{r}$ & 0.3827 & 0.1305 & 0.1307 & 0.1047 & 0.2303 & 0.1170 & 0.0736 & 0.0983 & 0.0786 & 0.0997 & 0.2830 \\
$t(\bar{r})$ & 3.1449 & 4.9925 & 5.2705 & 4.1943 & 1.8761 & 4.2646 & 3.4438 & 3.0910 & 2.5537 & 1.4235 & 2.0369 \\
$\alpha_{C A P M}$ & 0.3392 & 0.0983 & 0.0919 & 0.0632 & 0.1906 & 0.0776 & 0.0342 & 0.0707 & 0.0414 & 0.0654 & 0.2736 \\
$t\left(\alpha_{C A P M}\right)$ & 2.7105 & 4.0718 & 4.3776 & 3.0942 & 1.5079 & 3.2185 & 2.1106 & 2.2650 & 1.4513 & 0.9166 & 1.8991 \\
$\alpha_{3}(2 * 3)$ & -0.0412 & 0.0359 & 0.0242 & -0.0062 & 0.0397 & -0.0019 & -0.0059 & -0.0034 & -0.0411 & -0.0753 & 0.0339 \\
$t\left(\alpha_{3}\right)$ & -0.3482 & 1.4657 & 1.2347 & -0.3350 & 0.7823 & -0.0848 & -0.3529 & -0.1040 & -1.4738 & -0.9865 & 0.2166 \\
$\alpha_{3}(2 * 2)$ & 0.0180 & 0.0556 & 0.0488 & 0.0182 & 0.1324 & 0.0278 & 0.0069 & 0.0210 & -0.0144 & -0.1157 & 0.1335 \\
$t\left(\alpha_{3}\right)$ & 0.1603 & 2.3109 & 2.3900 & 0.9576 & 1.4707 & 1.1818 & 0.4229 & 0.6596 & -0.5207 & -1.7930 & 0.8645 \\
\hline
\end{tabular}

\section{Conclusions and remarks}

This paper shows mainly that network hype is an important factor in promoting the increase in cryptocurrency prices, and the three-factor pricing model we construct can explain the cryptocurrency excess returns. We use Google attention innovation as the measure for network hype and develop a factor model applied in cryptocurrency market. This paper challenges a new relationship between network hype and cross-sectional expected cryptocurrency market returns. Using Fama-MacBeth regression approach, we find mainly a positive relation between Google attention innovation and the cross-sectional cryptocurrency market expected returns. And the positive relation is robust when we control other variables including size, momentum, reversal, and MAX. We further construct a three-factor pricing model composed of the cryptocurrency market factor, size factor, and network hype factor. For testing the performance of the pricing model, we divide cryptocurrencies into 25 portfolios and then regress 25 portfolios on the factor model we construct. In addition, GRS test method (Gibbons et al., 1989) validate the result of regression.

The paper represents an important reference for cryptocurrency investors and has implications that all investors should be more rationally aware that network hype can promote cryptocurrency prices and they should recognise that network hype is 
an invisible accelerator for the expansion of the cryptocurrency market. Note that Google Trends viewed as media attention relates to news and information about cryptocurrencies. Investors investing cryptocurrencies are likely to suffer from huge loss due to fake network information. Hence, for regulators, cryptocurrency issuers should be supervised strictly, and the cryptocurrency information should be more closely regulated to avoid misleading investors.

Our work opens an new direction for the asset pricing in cryptocurrency market and several research can be further considered based on our work. Such as, quantitative investment in crytocurrency market, the determination factors of the price of the cryptocurrencies and the efficiency checking of the cryptocurrency market.

\section{Acknowledgements}

We would like to thank seminar participants at Central South University, the 2nd FinTech Conference in JUFE. This work is supported by the National Natural Science Foundation of China $(72071098,71771107)$ and thousands of people plan of high-level financial experts project of Jiangxi Province (jxsq2019201130).

\section{References}

Aloosh, A. and Ouzan, S. (2019) 'The psychology of cryptocurrency prices', Financial Research Letter, in press [online] https://doi.org/10.1016/j.frl.2019.05.010.

Amihud, Y. (2002) 'Illiquidity and stock returns: cross-section and time-series effects', Journal of Financial Markets, Vol. 5, No. 1, pp.31-56.

Antonakakis, N., Chatziantoniou, I. and Gabauer, D. (2019) 'Cryptocurrency market contagion: market uncertainty, market complexity, and dynamic portfolios', Journal of International Financial Markets, Institutions and Money, Vol. 61, No. 1, pp.37-51.

Athey, S., Parashkevov, V.S.I. and Xia, J. (2016) Bitcoin Pricing, Adoption, and Usage: Theory and Evidence, Stanford University Graduate School of Business Research Paper, No. 16-42 [online] https://ssrn.com/abstract=2826674.

Bali, T.G., Cakici, N. and Whitelaw, R.F. (2011) 'Maxing out: stocks as lotteries and the cross-section of expected returns', Journal of Financial Economics, Vol. 99, No. 2, pp.427-446.

Barillas, F. and Sheanken, J. (2018) 'Comparing asset pricing models', Journal of Finance, Vol. 73, No. 2, pp.715-754.

Bariviera, A.F. (2017) 'The inefficiency of Bitcoin revisited: a dynamic approach', Economics Letters, Vol. 161, pp.1-4.

Biais, B., Bisire, C., Bouvard, M. and Casamatta, C. (2019) 'The blockchain folk theorem', The Review of Financial Studies, Vol. 32, No. 5, pp.1662-1715.

Borri, N. (2019) 'Conditional tail-risk in cryptocurrency markets', Journal of Empirical Finance, Vol. 50, No. 1, pp.1-19.

Borri, N. and Shakhnov, K. (2018) Cryptomarket Discounts, Working Paper [online] https://ssrn.com/ abstract $=3124394$.

Borri, N. and Shakhnov, K. (2019) The Cross-Section of Cryptocurrency Returns [online] https:// ssrn.com/abstract=3241485 or http://dx.doi.org/10.2139/ssrn.3241485.

Caporale, G.M. and Plastun, A. (2019) 'Price overreactions in the cryptocurrency market', Journal of Economic Studies, Vol. 46, No. 5, pp.1137-1155. 
Carhart, M.M. (1997) 'On persistence in mutual fund performance', Journal of Finance, Vol. 52, No. 1, pp.57-82.

Cheng, J. and Dai, Y. (2020) 'Is Bitcoin a channel of capital inflow? Evidence from carry trade activity', International Review of Economics \& Finance, Vol. 66, No. 2, pp.261-278.

Cong, L.W., Lix, Y. and Wang, N. (2018) Tokenomics: Dynamic Adoption and Valuation, Working Paper.

Corbet, S., Lucey, B., Urquhart, A. and Yarovaya, L. (2019) 'Cryptocurrencies as a financial asset: a systematic analysis', International Review of Financial Analysis, Vol. 62, No. 1, pp.182-199.

Da, Z., Engelberg, J. and Gao, P. (2011) 'In search of attention', Journal of Finance, Vol. 66, No. 5, pp.1461-1499.

Elendner, H., Trimborn, S., Ong, B. and Lee, T.M. (2018) 'The cross-section of cryptocurrencies as financial assets: investing in cryptocurrencies beyond Bitcoin', Handbook of Blockchain, Digital Finance, and Inclusion, Vol. 1, pp.145-173, Cryptocurrency, FinTech, InsurTech, and Regulation.

Fama, E.F. and French, K.R. (1992) 'The cross section of expected stock returns', Journal of Finance, Vol. 47, No. 2, pp.427-465.

Fama, E.F. and French, K.R. (2015) 'A five-factor asset pricing model', Journal of Financial Economics, Vol. 116, No. 1, pp.1-22.

Fama, E.F. and MacBeth, J.D. (1973) 'Risk, return, and equilibrium: empirical tests', Journal of Political Economy, Vol. 81, No. 3, pp.607-636.

Gibbons, M.R., Ross, S.A. and Shanken, J. (1989) 'A test of the efficiency of a given portfolio', Econometrica, Vol. 57, No. 5, pp.1121-1152.

Hou, K., Xue, C. and Zhang, L. (2015) 'Digesting anomalies: an investment approach', The Review of Financial Studies, Vol. 28, No. 3, pp.650-705.

Hu, A.S., Parlour, C.A. and Rajanzx, U. (2018) Cryptocurrencies: Stylized Facts on a New Investible Instrument, Working Paper.

Iyidogan, E. (2018) Economic Model of Blockchain Based Cryptocurrencies, Working Paper.

Jegadeesh, N. and Titman, S. (1993) 'Returns to buying winners and selling losers: implications for stock market efficiency', Journal of Finance, Vol. 48, pp.65-91.

Köchling, G., Müller, J. and Posch, P.N. (2019) 'Does the introduction of futures improve the efficiency of Bitcoin?', Finance Research Letters, Vol. 30, No. 1, pp.367-370.

Klein, T., Pham Thu, H. and Walther, T. (2018) 'Bitcoin is not the New Gold - a comparison of volatility, correlation, and portfolio performance', International Review of Financial Analysis, Vol. 59, No. 1, pp.105-116.

Kristoufek, L. (2013) Bitcoin meets Google Trends and Wikipedia: Quantifying the Relationship between Phenomena of the Internet Era, Science Report, No. 3, p.3415, DOI: 10.1038/srep03415.

Kristoufek, L. (2018) 'On Bitcoin markets (in)efficiency and its evolution', Physica A: Statistical Mechanics and its Applications, Vol. 503, No. 1, pp.257-262.

Li, J. and Mann, W. (2018) Initial Coin Offering and Platform Building, Working Paper.

Liu, Y. and Tsyvinski, A. (2018) Risks and Returns of Cryptocurrency, NBER Working Paper, No. 24877.

Liu, Y., Sheng, J. and Wang, W. (2019) Do Digital Coins Have Fundamental Values? Evidence from Machine Learning, Working Paper [online] http://pdfs.semanticscholar.org.

Makarov, I. and Schoar, A. (2018) Trading and Arbitrage in Cryptocurrency Markets, NBER Working Paper.

Malinova, K. and Park, A. (2017) Market Design with Blockchain Technology, Working Paper.

Nadarajah, S. and Chu, J. (2017) 'On the inefficiency of Bitcoin', Economics Letters, Vol. 150, No. 1, pp.6-9. 
Nakamoto, S. (2008) Bitcoin: A Peer-to-Peer Electronic Cash System, Self-published White Paper [online] https://bitcoin.org/bitcoin.pdf.

O'Hara, M. (2003) 'Presidential address: liquidity and price discovery', The Journal of Finance, Vol. 58, No. 4, pp.1335-1354.

Saleh, F. (2018) Volatility and Welfare in a Crypto Economy, Working Paper, McGill University.

Stavroyiannis, S. (2018) Value-at-Risk and Related Measures for the Bitcoin, Working Paper.

Takeda, F. and Wakao, T. (2014) 'Google search intensity and its relationship with returns and trading volume of Japanese stocks', Pacific-Basin Finance Journal, Vol. 27, No. 1, pp.1-18.

Tinn, K. (2018) Blockchain and the Future of Optimal Financing Contracts, Working Paper.

Urquhart, A. (2016) 'The inefficiency of Bitcoin', Economic Letter, Vol. 148, No. 1, pp.80-82.

Urquhart, A. and Zhang, H. (2017) Is Bitcoin a Hedge or Safe-Haven for Currencies? An Intraday Analysis, Working Paper.

Yang, H. (2019) Behavioral Anomalies in Cryptocurrency Markets [online] https://ssrn.com/abstract= 3174421.

Yong J., He, N. and Weihua, R. (2018) 'Time-varying long-term memory in Bitcoin market', Finance Research Letters, Vol. 25, No. 1, pp.280-284.

\section{Notes}

1 Because the time span of the cryptocurrency sample covers only 109 weeks and is short relative to the stock market data, we short the return frequency from a month to a week.

2 We consider the longer-term lag effects of the change of Google Trends on cryptocurrency. But the empirical results are not significant. Thus we only give the first three-order lag impact in Table 3. This indicates that the less impact of the change of Google Trends with the larger $k$, which is consistent with the network hype short-term effect.

3 The risk-free return is the weekly returns on US Treasury bills with one year maturity.

4 To determine the impact of the factor constructing approach on the performance of the pricing model, we also consider a $2 * 2$-factor constructing method. The steps are same as the $2 * 3$-factor constructing method. 